\title{
Delayed-onset dystonia in patients with "static" encephalopathy
}

\author{
ROBERT E BURKE, STANLEY FAHN, AND ARNOLD P GOLD
}

From the Department of Neurology, Columbia University College of Physicians and Surgeons, and The Neurological Institute, New York

SUMMARY Eight cases of persistent dystonia appearing one to 14 years after non-progressive cerebral insults are described. Five were due to perinatal anoxia, one to trauma, and two to cerebral infarction. This phenomenon of delayed-onset dystonia has not been described previously, although review of earlier literature reveals several probable examples. Delayed-onset dystonia due to perinatal anoxia is an important diagnostic alternative to dystonia musculorum deformans for dystonia occurring in childhood.

Abnormal involuntary movements may he caused by non-progressive cerebral insults. Choreic, athetoid and dystonic movements due to perinatal anoxia or kericterus, ${ }^{1}$ and ballistic, choreic and athetoid movements due to cerebral infarction $^{2}$ have been documented. In addition, abnormal involuntary movements have been reported after trauma, anoxia or carbon monoxide poisoning in the adult. $^{34}$

In general, the abnormal involuntary movements in such cases appear either (1) at the time the insult occurs, (2) when the acute neurologic deficit resolves, or (3) when the patient matures neurologically, as in the case of perinatal insults. In a study of the natural history of choreoathetoid cerebral palsy, Polani ${ }^{1}$ found that of 56 patients, 39 had abnormal involuntary movements by the age of $2 \frac{1}{2}$ years, and the other 17 had abnormal involuntary movements by the age of $3 \frac{1}{2}$ years. These data are supported by the observations of Crothers and Paine $^{5}$ who noted that the majority of patients with "extrapyramidal" cerebral palsies were first seen between the ages of 10 and 18 months because of abnormal motor development. As these children grew older, abnormal involuntary movements developed. Paine ${ }^{6}$ serially evaluated children with perinatal brain injury and noted that of those who ultimately developed choreo-athetosis or dystonia, $92 \%$ showed visible chorea or athetosis by the age of three years. The abnormal move-

Address for reprint requests: Dr Robert E Burke, Neurological Institute, 710 West 168th Street, New York, NY 10032, USA.

Accepted 1 May 1980 ments seen in an individual case of cerebral palsy can change radically in their character at later ages. ${ }^{7}$ Lesny $^{8}$ documented a change between the ages of five and 14 years from athetosis to a "wholly different condition," that is, chorea, "tension spasm," or "tension athetosis," in 45 of 100 cases of athetoid cerebral palsy. These cases of dystonic movements, however, occurred in the setting of pre-existing different abnormal involuntary movements, which were apparent since early infancy.

The abrormal involuntary movements which develop after cerebral infarction occur acutely or as the patient recovers from the initial hemiplegia. This temporal sequence is typical of hemiballism and hemichorea, ${ }^{910}$ and appears to hold true in many of the published cases of post-hemiplegic athetosis, where information is provided as to the onset of the abnormal movements in relation to the initial event. ${ }^{211-18}$

In contrast to these cases in which the movements appear soon after the insult or as part of an evolving picture in relation to the insult, we have seen several patients in whom dystonic movements appeared and progressed in severity cne or more years after an original insult. In the interval between the initial event and the subsequent appearance of the movements, these fatients had minimal or no neurological abnormalities which, most importantly, were entirely static until the appearance of the abnormal movements. We considered these movements as dystonic when they were sustained, involuntary twisting movements affecting muscles of the limbs, trunk, neck or face. ${ }^{19}$ The terms 
focal, segmental and generalised dystonia are used as defined by Marsden. ${ }^{7}$ Similar cases have been reported by Hanson, Berenberg and Byers. ${ }^{20}$ They described three children who suffered cerebral anoxia in early life, with mild but stable subsequent motor dysfunction, who developed tremors, athetosis, or dystonic movements at ages five to 15 years, which then progressed in severity.

This phenomenon of delayed-onset dystonia merits recognition because it represents a previously neglected diagnostic consideration, especially for dystonia occurring in adolescence. Furthermore, the existence of this phenomenon may shed some light on the pathogenesis and pathophysiology of dystonic movements.

\section{Case histories}

\section{Perinatal anoxia}

Case 1 This child developed dystonic movements of the left arm and leg at the age of seven years. She was the product of a normal, full-term pregnancy, but delivery was complicated, necessitating the use of forceps. Apgar Score at one minute was 3. She apparently did well in the early neonatal period and was discharged after four days. Developmental milestones were acquired normally: she walked at seven months, said words at one year, and spoke in sentences at two years. She had no problem learning to ride a bicycle or tie shoe laces, but she was considered to be a "clumsy child." Her speech was indistinct and she received speech therapy. Initially there were academic difficulties, and for that reason formal psyohometry was done, which demonstrated a "very superior range of intelligence."

At the age of seven years the child developed progressive difficulty with walking and using her left hand. The parents noted that when the child walked or climbed stairs, she tended to rotate externally the left leg, the left arm would become pronated with the wrist and fingers flexed. There was no history of head trauma, drug ingestion, or change in intellect. There was no family history of neurologic illness. The mother and father were of Scottish and Irish descent, respectively. Over eight months, the abnormal posturing became more severe and she was admitted to another hospital for evaluation at the age of eight years. On examination, the child was alert and of normal intelligence. Her speech was indistinct. Head circumference was normal. When walking, she oircumducted and externally rotated the left leg, and she had at times a "dystonic posture of the left foot." When running she would flex and markedly pronate the left arm. She was said to have a mild left hemiparesis affecting distal musculature of arm and leg. Cranial nerves, cerebellar testing, deep tendon reflexes, and sensation were normal. The right plantar reflex was flexor, the left was equivocal. Normal or negative tests included complete blood count (CBC), urinalysis, electrolytes, renal and liver function tests, serum ceruloplasmin, antinuclear antibody (ANA) and skull radiographs. An electroencephalogram (EEG) showed background disorganization, bilateral slowing, and intermittent sharp waves with a left-sided predominance. Cerebrospinal fluid (CSF) contained no cells, glucose of $3.7 \mathrm{mmol} / 1$, protein of $0.32 \mathrm{~g} / \mathrm{l}$, with a gamma globulin fraction of $16 \%$ (normal, $12 \%)$. A slit-lamp examination was negative. A computed tomography (CT) scan showed right cerebral hemiatrophy, with enlargement of the right frontal horn, right atrium and sulci over the right convexity. She was discharged, but because of progressive gait difficulty she was readmitted after two months. Repeat examination showed marked dystonic posturing of the left arm and leg. Repeat serum ceruloplasmin was normal; serum thyroxine was normal. CSF contained a protein of $0 \cdot 21 \mathrm{~g} / 1$, and a gamma globulin of $7.3 \%$. A four-vessel cerebral angiogram was normal. She was referred to the Neurological Institute and examined by us 10 months after the onset of the abnormal movements. On examination, there were twisting abnormal involuntary movements of the left arm and leg when she sat at rest. The left shoulder was elevated and the arm extended at the elbow. The foot was plantar flexed with equinovarous posturing. When she walked, there was abduction of the arm, lifting the arm in the air. The right side was not involved. There was no weakness, reflexes were symmetric, and plantar reflexes were flexor. At follow-up examination 18 months after the onset, the affected arm and leg were unchanged, but she had developed a slight head tilt to the left.

Case 2 This boy developed dystonic movements of the right forearm at the age of 14 years. Records of his birth indicate he was the product of a full term pregnancy. There was premature rupture of the membranes, and labour was 12 hours in duration. Delivery was complicated by a breech presentation with prolapse of the cord, requiring reposition of the extremities and forceps. Apgar Score at one minute was zero. The child was resuscitated and placed in an incubator with oxygen. He slowly improved and was discharged after one week. The mother was told that the child was "probably brain damaged."

At the age of two years the child was seen here in the Pediatric Clinic. The mother, who had had two previous normal children, thought this child's development may have been slow, but the attending pediatrician considered the child to be normal. Skull radiographs and an EEG were normal. At the age of three years, the child was said to have indistinct speech. The child apparently developed normally thereafter, keeping up with other children athletically. Indistinct speech was a persistent problem and speech therapy was prescribed until the age of 11 years. His performance in school otherwise was average. 
An intermittent tremor of the right hand was observed at the age of 11 years, and at 14 years, twisting movements of the right hand appeared, which necessitated a change to writing with the left hand. There was no history of head trauma, drug ingestion or change in intellect. Both parents were of Irish descent, and there was no history of neurological illness in the family.

Other than a questionable right hemiparesis, examination revealed abnormal movements of the right hand "resembling chorea." Intellect, cerebellar function and sensation were normal. CBC, urinalysis, electrolytes, sedimentation rate, skull films, serology for syphilis and a CT scan were negative or normal. CSF contained no cells and a protein of $0.27 \mathrm{~g} / 1$, and glucose of $3.8 \mathrm{mmol} / 1$. An EEG showed bursts of generalised 4-6 $\mathrm{Hz}$ spike and slow waves. There were no focal abnormalities.

Over the next two years, the abnormal involuntary movements of the right arm remained the same. The patient noted occasional "twitching" of the left thumb. Neurologic evaluation by us at the age of 16 years revealed sustained ulnar deviation of the right hand, which fluctuated in severity. The fingers of the right hand also had sustained ulnar deviation and were hyperextended at the metacarpophalangeal joints. There was no detectable weakness. Intermittent sustained extension at the left thumb distal interphalangeal joint was noted. The abnormal involuntary movements were made more severe by action, such as walking or finger-to-nose testing. Repeat blood count, urinalysis, electrolytes, CSF analysis, including gamma globulin, liver function tests, ceruloplasmin, slit-lamp examination, and repeat EEG were normal. The patient's mother and three sisters were examined and they were normal. Case 3 This boy developed dystonic movements of the left arm and trunk at the age of 13 years. He was the result of a full term, uncomplicated pregnancy. Labour was induced. The child was cyanotic at birth and required intubation with oxygen therapy for eight hours. Apgar score at one minute was 7. Developmental milestones were slightly delayed: he sat alone at eight months, walked unassisted at 15 months, began to speak at two years. His gait was awkward in early life and he cften fell for no apparent reason. He was not able to run until the age of five years. In kindergarten, when five years old his teacher raised the question of spasticity and mental retardation. There was no family history of neurologic disease.

Neurologic examination by us at the age of six years revealed a co-operative, alert child with mildly dysarthric speech and a fund of knowledge deficient for chronological age. Reproductions of BenderGestalt patterns were immature and suggestive of perceptual difficulty. His gait was spastic; the legs were stiff, and there was a tendency towards toe walking. Tone was increased, especially in the legs. Reflexes were generally hyperactive, but plantar responses were flexor. Mild cerebellar dysfunction was noted. A fine resisting tremor of the extremities and horizontal tremor of the head were noted.

The child did well until aged 13 years when the parents noted episodes in which his head and trunk were pulled to the left. These movements were associated with a forward protrusion on the left shoulder and extension of the left arm backwards. The movements became more severe, and after evaluation at two other institutions, he was referred here.

On examination, the child had a poor fund of knowledge, and spelling and mathematics were at a third grade level. Graphomotor skills were deficient. His gait was spastic with slight flexion at the hips and knees. There was mild weakness of the hands. Tone was generally increased, with hyperactive deep tendon reflexes and bilateral extensor plantar reflexes. Cerebellar testing showed mild dysmetria. Sensation was normal. No Kayser-Fleischer rings were noted. Examination of his abnormal movements revealed intermittent torticollis with the chin pulled left and intermittent scoliotic posturing with the thoracic spine being convex to the right. The left shoulder was elevated and pulled anteriorly. When the patient walked, the left arm was pulled backwards, with the arm extended at the elbow. Occasional athetotic flexion and extension movements of the right fingers were noted. Chest x-ray showed mild pectus carinatum. CBC, urinalysis, skull radiographs, CSF analysis and a CT scan were normal.

After discharge, benzhexol was started and the abnormal movements lessened. At follow-up, 20 months after the onset of the movements, he remained improved with only occasional dystonic movements of the left shoulder, precipitated by stress, or by missing doses of benzhexol.

Case 4 This boy developed dystonic movements of the right arm and the neck at age nine years. The child was cyanotic at birth with apnoea and no heart beat. He was examined by us at the age of four months, and the only abnormal findings were increased tone in legs and generalised hyperreflexia. Re-examination at one year showed that the child was able to walk unassisted, but there was increased tone in the legs with poor prehensile function. At 17 months, a left hand preference was noted in addition to a right-sided reflex preponderance. At $2 \frac{1}{2}$ years, the right hemiparesis was more marked. Language function was well-developed, but speech was slurred. Skull radiographs, radionuclide brain scan and CSF analysis were normal. An EEG showed left focal spike discharges. Subsequent intellectual function and motor performance developed normally, but the parents observed difficulty with fine movements such as tying shoe laces and buttoning.

At the age of nine years he developed a head tilt to the right and abnormal involuntary movements of the right arm. Examination revealed indistinct speech, moderate head tilt to the right, and posturing of the right arm when walking. The abnormal movements involved the shoulder as well 
as the hand. Four months later, the child awoke and could not walk because of marked pain in his gastrocnemii with equinus posturing of the feet, and then these symptoms promptly resolved. Examination showed normal intellect (full scale IQ 118). Gait was characterised by a diminished arm swing on the right, and a tendency to toe walk on the right. The head was tilted to the right, and both arms had "rapid irregular jerky movements associated with slow writing movements." CBC, urinalysis, sedimentation rate, CSF analysis, ceruloplasmin, radionuclide brain scan, pneumoencephalogram, and slit-lamp examination were normal. An EEG showed occasional spike discharges in the left central and posterior temporal areas with diffuse slowing, more prominent on the left. The child was treated, with transient success, with levodopa. but it was discontinued after a few weeks when it seemed no longer effective.

At 11 years of age, two years after the onset of the movements, repeat examination revealed torticollis with head tilted to the right. The right arm was intermittently internally rotated and elevated at the shoulder. The right forearm continuously assumed a sustained supination posture. The fingers of the right hand were flexed. The left arm was intermittently internally rotated proximailly. All abnormal movements were aggravated by action, for example, writing or walking. At rest, there were no abnormal movements of the legs. With walking, the right foot plantar flexed and the leg internally rotated. Strength was normal. Repeat psychometrics at that time showed a full scale IQ of 110 . At 13 years of age, benzhexol was begun, with some improvement.

Case 5 This boy developed dystonic movements of the trunk, right arm and leg at the age of $6 \frac{1}{2}$ years. He was the result of a full term, normal pregnancy Delivery was reported to be normal, but the birth records were not detailed. The mother was not aware of any postnatal respiratory difficulty. However, developmental milestones were abnormal, with an inability to stand unsupported until 20 months, to walk unassisted until aged two years, and to speak in phrases until six years old. At the age of 18 months, the child was diagnosed by a family physician to have cerebral palsy.

When the child was $6 \frac{1}{2}$ years old, the parents noted rapid jerks of the arm and head, and sustained abnormal positions of the head. At another hospital, CSF analysis and a CT scan were normal. An EEG showed epileptiform activity over both hemispheres. Treatment with clonazepam resulted in worsening of the movements. There was no family history of neurologic disease.

The child was examined by us at the age of $7 \frac{1}{2}$ years. Intellect was normal. Speech was dysarthric, with frequent drooling. The gait was mildly broadbased with a tendency to toe walk. Tone was generally increased, and reflexes were hyperactive. The plantar responses were flexor. There were two types of abnormal involuntary movements. There were sudden myoclonic jerks of the head and arms, often in a series, and there were dystonic movements. On standing, the child leaned backward in an opisthotonic position. The head would either turn to the left or be retroflexed. The right arm was flexed at the elbow and wrists, and abducted at the shoulder. The right leg would be thrust forward with flexion at the knee. A CBC, electrolytes, sedimentation rate, liver function tests, acid-base studies, serum ceruloplasmin, CT scan, and visual evoked responses were normal or negative. An EEG showed epileptiform discharges over the right occipital region. The movements responded to benzhexol. At follow-up examination, two years later while the child remained on benzhexol, there was no evidence of progression.

\section{Craniocerebral trauma}

Case 6 This girl developed abnormal movements of the right arm and leg six years after craniocerebral trauma. The child was normal until two years old when, in an automobile accident, she suffered a depressed skull fracture on the left. She was admitted to another hospital in coma with a right hemiparesis. The child slowly recovered from this injury. Initially she was aphasic, but over two months her speech became normal. Function in the right arm and hand improved, but she never regained fine dexterity in the right hand, and she changed to being left-handed. Her gait also improved, and six years after the accident she no longer needed a foot brace. Diphenylhydantoin was given for six months after the accident and she never had seizures after it was discontinued.

Six years after the accident, the child developed right sided "choreo-athetotic movements" and she was referred here. Family history was negative for neurologic disease. On examination her intellect was normal. Graphomotor function was performed awkwardly with her right hand. There was a mild right hemiparesis involving primarily the hand and foot, with a right reflex preponderance, and an extensor right plantar response. "Sinuous" movements of the right arm and leg, and right paraspinal muscle spasm were noted. She was treated with diazepam and perphenazine.

Three years after the onset of the movements, aged 11 years, she was examined by one of us. At that time, she did not have any rapid choreic movements. At rest, she had occasional writhing, athetoid movements of the hand. When she used the arm, for example, for writing or picking up objects, dystonic movements became apparent. The hand would develop sustained flexion and median deviation at the wrist. When standing, she had intorsion of the right foot. When she walked or ran, she developed marked internal rotation of the right leg and flexion of the hip.

\section{Cerebral infarction}

Case 7 This woman developed dystonic movements one year after a probable cerebral infarction. At 
the age of 65 years, a left hemiparesis occurred abruptly and then resolved completely within 24 hours. She never had sensory complaints. Six months later, a thermogram revealed dense coldness over the right side of her face.

One year after the stroke, she noted a "hard spot" in her left triceps. She progressively developed sustained flexion at the elbow, wrist and fingers. She had difficulty opening her jaw and had a sensation of "tightness" over the left side of her face. Levodopa, amantadine, propranolol, and carbamazepine were not effective in treating these movements.

She was examined here two years after the onset of the movements. Intellect and speech were normal, as were cranial nerves, strength, cerebellar function and sensation. Reflexes were not obtained in the lefit arm, but otherwise were intact and symmetric. Plantar responses were flexor. The left arm was abducted at the shoulder and it was flexed at the elbow and wrist. The first three fingers were flexed at the metacarpophalangeal and proximal interphalangeal joints. There was a notable limitation of jaw opening. CBC, electrolytes, lupus erythematosis preparation, serum thyroxine, serology for syphilis, CSF were normal or negative. Skull radiographs and brain scan were negative. An EEG was mildly abnormal, showing nonspecific intermittent bitemporal slowing. A CT scan showed mild generalised atrophy and a lucency in the right cerebral hemisphere consistent with an infarction in the distribution of the right middle cerebral artery. An arteriogram showed a complete occlusion of the right internal carotid artery. An EMG showed activity at rest in agonist and antagonist muscles of the left arm.

Case 8 This man developed dystonic movements of the left arm one year after a cerebral infarction. The patient was well until the age of 54 years, when he had sudden onset of bilateral arm and leg "heaviness" with a tendency to fall to the left. At another hospital, examination revealed mild left facial, arm and leg weakness. CSF, brain scan, and EEG were normal. The weakness resolved in a few days, and the patient returned to work.

One year later, the patient fell and struck his left wrist. One month after this injury, he developed abnormal involuntary movements of the left arm. On examination here, the patient was normal, with the exception of left leg hyperreflexia and an extensor plantar response on that side. There were marked dystonic movements of the left arm: the shoulder was pulled backwards and upwards; the first two fingers were flexed, the third and fourth were extended and abducted. The left great toe was held in constant dorsiflexion. CBC, urinalysis, electrolytes, ESR, protein electrophoresis, ceruloplasmin and CSF analysis were normal or negative as were EEG, CT scan, radionuclide brain scan and brainstem auditory evoked responses. An EMG at rest showed intermittent, simultaneous activity in the left biceps and triceps.
At follow-up, one year after onset of the movements, the movements were unchanged.

\section{Literature review}

It is often the case that a phenomenon not previously emphasised in the literature nevertheless is evident in some prior reports. We reviewed most of the cases of dystonia reported in the English literature since the description by Schwalbe. ${ }^{21}$ The very complete literature reviews by $\mathrm{Herz}^{22}$ and Eldridge ${ }^{23}$ were supplemented by reviews of more recent reports. We summarise briefly cases in which adequate data are available and which we feel are probably representative of delayed-onset dystonia.

\section{Perinatal anoxia}

Herz ${ }^{22}$ Case 10 This boy developed dystonic movements at the age of eight years. He was born after a full term pregnancy. Delivery was by forceps. He had several convulsions in the postnatal period, but none afterwards. Early development was slow, and he walked at $2 \frac{1}{2}$ years. His gait was said to be stiff, but he was "able to play ball and get around fairly well." He apparently toe-walked and bilateral obturator sections were done at the age of eight years to improve his gait. Involuntary movements of the extremities began before the procedure and became worse afterwards. Examination at the age of 18 years revealed normal intellect and a scissors gait. The patient's trunk was bent and turned to the left. Slow, sustained, twisting movements involved the arms and legs. This patient was diagnosed by Herz to have dystonia musculorum deformans. Family history is not mentioned.

Ryan $^{24}$ This girl developed dystonic movements at aged four years. She was born of a normal pregnancy, but delivery extended over a period of two days, culminating in a forceps extraction with cyanosis at birth. Infancy, however, was said to be normal. The child walked alone at 18 months. Development continued to be considered normal until the age of four when she fell, injuring her left leg. She was hospitalised and said to have "hysterical spasm" of the dorsiflexors of the left foot. This "spasm" apparently persisted until aged seven years, when it improved, although the child continued to walk on the outside of her shoe. At the age of 10 years, three weeks after a fall, the child developed retrocollis, arching of the back and dystonic postures of the limbs. No Kayser-Fleischer rings were noted; liver function tests and CSF were normal. There was no family history of neurologic illness. This patient was reported as a case of dystonia musculorum deformans.

Hanson, Berenberg, and Byers ${ }^{20}$ This boy developed a tremor at the age of 11 years; at the age of 14 years he developed "flexion spasms" of the neck. The pregnancy was normal. The child was a breech presentation and born with the cord looped around his neck. There were no spontaneous respirations for 25 minutes. Motor development 
was slow; he sat aged 18 months and walked alone aged $2 \frac{1}{2}$ years. No neurologic abnormalities were recognised by the family physician. At the age of 11 years he began to develop slurred speech and a tremor of the left arm. At the age of 14 years, he developed flexor spasms of the neck which were worse when walking. Subsequently, facial grimacing and choreoathetosis of the arms appeared.

\section{Craniocerebral trauma}

Messimy, Diebler and Metzger ${ }^{25}$ A 30-year-old man suffered right sided head trauma in an auto accident. There was no loss of consciousness. Four years later, he developed dystonic movements of the left arm. A CT scan showed calcification of the right caudate nucleus.

\section{Cerebral infarction}

Denny-Brown ${ }^{26}$ A patient was said to have suddenly developed a mild hemiparesis with sensory loss due to a cerebral embolus. The patient recovered completely except for some mild residual facial numbness. Eleven months after this episode, "there began a progressive flexion of the wrist and fingers, spreading to the elbow after a further three months, and eventually leading to severe dystonic flexion of the arm and neck."

\section{Discussion}

To summarise in each of the cases presented, a presumably non-progressive cerebral insult was followed by a period of neurologic stability for one to 14 years. During this period, the patients had mild or no neurologic deficit. They then developed abnormal dystonic movements which progressed in severity over a period of months to years, but then stabilised. The dystonic movements in each case were persistent. Clinical data for cases of dystonia secondary to perinatal anoxia are contained in the table.

To make plausible the possibility of a causal relationship between the original insult and the delayed-onset dystonia in these cases, we must exclude other possible aetiologies of dystonia. ${ }^{2 i}$ In cases 6,7 , and 8 , the somatotopic correspondence between the initial neurologic manifestations and the subsequent dystonic movements make a causal relationship quite likely. In these patients there was no intellectual decline or other neurologic manifestations to suggest a central nervous system degenerative or metabolic disease, for example Huntington disease, Parkinson disease, Wilson disease, HallervordenSpatz disease or a lipidosis. There was no history of encephalitis or drug ingestion. In cases 7 and 8, mass lesions were excluded by appropriate studies, and in case 6 a mass lesion was improbable on clinical grounds. These three cases are examples of the recognized causal relationship between dystonic movements and prior head trauma or stroke, ${ }^{27}$ but we report them as examples of a marked delay between the insult and the onset of the movements, which has not previously been emphasized.

In Cases 1 to 5, lack of intellectual decline or other neurological signs mitigate against degenerative and metabolic diseases. Wilson disease was excluded in each case. There was no prior history of drug ingestion or encephalitis and a mass lesion was excluded in each case. It is more difficult to exclude dystonia musculorum deformans (hereditary and idiopathic torsion dystonia) in these cases, because at present dystonia musculorum deformans is diagnosable only on the basis of clinical and genetic criteria, and when known secondary causes of dystonia are excluded. The clinical expression of dystonia musculorum deformans can be quite variable, with some cases being nonprogressive and monosymptomatic. ${ }^{28} \mathrm{~A}$ negative family history for neurological disease does not exclude a genetically recessive form of the disease, nor a dominant form, because formes frustes exist and may

Table Delayed-onset dystonia following perinatal anoxia

\begin{tabular}{|c|c|c|c|c|c|c|c|}
\hline Case & $\begin{array}{l}\text { Birth } \\
\text { complication }\end{array}$ & $\begin{array}{l}\text { Apgar } \\
\text { score }\end{array}$ & $\begin{array}{l}\text { Motor } \\
\text { development }\end{array}$ & $\begin{array}{l}\text { Age of onset } \\
\text { dystonia }\end{array}$ & $\begin{array}{l}\text { Site of } \\
\text { involvement }\end{array}$ & $\begin{array}{l}\text { Length of } \\
\text { follow-up after } \\
\text { onset }\end{array}$ & $\begin{array}{l}\text { Evidence of } \\
\text { progression at } \\
\text { most recent } \\
\text { follow-up }\end{array}$ \\
\hline $\begin{array}{l}1 \\
2\end{array}$ & $\begin{array}{l}\text { Forceps } \\
\text { Breech, cord } \\
\text { prolapse, forceps }\end{array}$ & $\begin{array}{l}3 \\
0 \\
5\end{array}$ & $\begin{array}{l}\text { Normal } \\
\text { Normal }\end{array}$ & $\begin{array}{l}7 \\
14\end{array}$ & $\begin{array}{l}\text { Left arm and leg } \\
\text { Right arm }\end{array}$ & $\begin{array}{l}18 \text { months } \\
2 \text { years }\end{array}$ & $\begin{array}{l}\text { Minimal } \\
\text { None }\end{array}$ \\
\hline 3 & Cyanosis & 7 & Abnormal & 13 & $\begin{array}{l}\text { Left arm, neck, } \\
\text { trunk }\end{array}$ & 20 months & None \\
\hline 4 & Cyanosis & $\mathbf{0}$ & Abnormal & 9 & $\begin{array}{l}\text { Right arm and } \\
\text { leg, neck }\end{array}$ & $3 \frac{1}{2}$ years & None \\
\hline 5 & Normal (?) & NA & Abnormal & $6 \frac{1}{2}$ & $\begin{array}{l}\text { Right arm and } \\
\text { leg, neck and } \\
\text { trunk }\end{array}$ & 2 years & None \\
\hline
\end{tabular}

NA-Not available 
go unrecognized by family members. ${ }^{23} 29$ However, several features of our cases are against a diagnosis of dystonia musculorum deformans. In Cases 1, 4 and 5, the dystonic movements were predominantly unilateral involving the arm and leg, and apparently stable after $1 \frac{1}{2}, 3 \frac{1}{2}$ and 2 years follow-up, respectively. In Marsden and Harrison' ${ }^{30}$ series which specifically excluded patients with an abnormal perinatal history, $79 \%$ of children with onset before the age of 11 years progressed to generalised dystonia. Among the 21 patients in their total series who did not progress, that is, who had segmental dystonia, none had unilateral arm and leg involvement. Furthermore, in both cases 1 and 4, there was evidence of a structural abnormality of the hemisphere contralateral to the side of the body affected by movements; an abnormal CT scan in Case 1, and an abnormal EEG in Case 4. These features are inconsistent with dystonia musculorom deformans. In Cases 2 and 3 there was likewise a negative family history, lack of progression, and predominantly focal involvement in Case 2 and segmental involvement in Case 3. In these cases the ipsilateral leg was not involved and there was no evidence of structural cerebral abnormality, so we cannot definitely exclude dystonia musculorum deformans. However, the similarity to Cases 1, 4 and 5, and lack of similarity to typical juvenile dystonia musculorum deformans, are against that diagnosis.

It is probable that our cases of delayed-onset dystonia subsequent to perinatal anoxia represent one end of a spectrum along which lie graduated degrees of neurological impairment and stability prior to the onset of abnormal movements. At the other end of the spectrum would be the well recognised cases of severe neurological impairment noted shortly after birth with development of abnormal movements in infancy. ${ }^{1568}$ That such a spectrum exists is suggested by "intermediate" cases such as Herz's ${ }^{22}$ Case 10. Although details regarding the child's development are lacking, he had a scissors, gait, which required bilateral obturator section, prior to the onset of dystonia. He was considered by Herz to represent a case of dystonia musculorum deformans. Our cases 3, 4 and 5 also suggest a continuum of neurological impairment, as they had neurologic abnormalities prior to the onset of the movements, unlike Cases 1 and 2. The existence of a continuum does not detract from the significance of the phenomenon of delayed-onset dystonia, especially in relation to the differential diagnosis of dystonia presenting in adolescence.
In the evaluation of dystonia presenting in adolescence, a suspected diagnosis of delayedonset dystonia does not obviate the need to consider possible structural, metabolic and degenerative causes. Where such evaluation has been unrevealing, however, the existence of delayed-onset dystonia following perinatal anoxia can be an important diagnostic alternative to dystonia musculorum deformans. Delayedonset dystonia is an important alternative not only from a clinical point of view in terms of appropriate prognosis and genetic counseling, but also from an investigative point of view, in terms of carefully defining a patient population representative of dystonia musculorum deformans. It is notable, for example, that in Eldridge's review ${ }^{23}$ of 145 patients considered to have dystonia musculorum deformans (11 of his total of 156 patients were acquired or atypical cases), a striking number of patients (40, or $28 \%$ ) had an abnormal delivery or developmental history where that information is provided. In his Category IV-A, that of sporadic cases of typical dystonia in non-Jewish individuals, there were two individuals with abnormal deliveries who each had two offspring (Ref: 23 table 20; families No 7 and 13). None of these four offspring apparently had dystonia at the time of the study, which would be unlikely if the two patients represented cases of spontaneous mutation to a dominant gene as suggested. It is conceivable that some of these cases may represent examples of delayed-onset dystonia. It may be desirable for investigators of dystonia musculorum deformans to specifically exclude patients with a history of perinatal anoxia, as did Marsden and Harrison. ${ }^{30}$

It is possible that perinatal anoxia can influence the expression of dystonia musculorum deformans. Eldridge ${ }^{23}$ reported a case of identical twins with this disease (Category IV-A, family 20 , fig 18), the second of whom had suffered perinatal anoxia and was more severely affected with dystonia. The question of whether such a relationship exists between dystonia musculorum deformans and perinatal anoxia is in need of further study. Also in need of further careful epidemiologic study is the question of a possible relationship between perinatal anoxia and other etiologies of dystonia, such as druginduced dystonias. There are several case reports implicating encephalopathy due to perinatal anoxia or other aetiologies in the occurence of drug-induced dystonia. Angle and McIntire ${ }^{31}$ reported a mentally retarded child, born of a precipitous labour at home, who developed per- 
sistent dystonia following accidental phenothiazine ingestion. However, the child also had previously suffered lead intoxication, and possibly encephalitis at the age of nine months. Furthermore, the child had ingested several other medications, including phenytoin. Angle, McIntire and Zetterman ${ }^{32}$ had previously reported an increased incidence of central nervous system manifestations, including abnormal involuntary movements, in children with an abnormal birth history among 1,033 cases of accidental drug ingestion, including phenothiazines. The type of abnormal involuntary movements was not specified. In addition, abnormal birth history was assessed as a risk factor only for incidence of central nervous system manifestations overall, not for incidence of abnormal involuntary movements specifically, or dystonia in particular. Simpson ${ }^{33}$ reported two particularly severe instances of butyrophenone-induced dystonia in two children with minimal brain dysfunction Chalhub, DeVivo and Volpe ${ }^{34}$ reported phenytoin-induced dystonia in an eight-year-old child with a static encephalopathy and seizure disorder subsequent to diphtheria-pertussis-tetanus immunisation at the age of six weeks. They suggested that the prior insult may have predisposed the child to the dystonic reaction. There is also a recent report ${ }^{35}$ of carbamazepineinduced dystonia in three children with preexisting brain damage; two with probable perinatal anoxia, and a third with agenesis of the corpus callosum.

The aetiology of dystonia musculorum deformans and the pathophysiology of the acquired dystonias remain unknown. There is no consistent pathologic abnormality in brains of patients with dystonia musculorum deformans. ${ }^{36}$ It is generally agreed that clinically similar disorders, such as dystonia associated with cerebral palsy, are associated with basal ganglia pathology, such as status marmoratus in the case of perinatal anoxia. The development of changing abnormal movements in cases of evolving "athetoid cerebral palsy" has generally been attributed to maturation of the developing central nervous system. ${ }^{7}{ }^{20}$ While this may be the case, the existence of delayed-onset dystonia subsequent to cerebral trauma and strokes in adults suggests one possible alternative explanation. The development and then persistence of dystonic movements years after an original cerebral insult suggests that they occur as a consequence of some anatomical or physiological change which takes place in the aftermath of the insult. Whereas traditionally the adult mam- malian central nervous system has been considered to lack regenerative potential, more recent work $^{37}$ indicates that sprouting of intact neurons takes place after an injury. Central nervous system sprouting has been demonstrated for monoaminergic ${ }^{38}$ and cholinergic ${ }^{39}$ systems. To speculate, it is conceivable that delayed-onset dystonia is caused by aberrant central nervous system sprouting subsequent to nonprogressive cerebral insult. However, how much such a process might relate, if at all, to the pathogenesis of dystonia musculorum deformans is impossible to suggest without a better understanding of that disease.

\section{References}

1 Polani PE. The natural history of choreo-athetoid "cerebral palsy." Guy's Hospital Reports 1959; 108:32-45.

2 Gowers WR. On "athetosis" and post-hemiplegic disorders of movement. Medico-Chirurgical Transactions 1876; 59:271-325.

3 Fahn S. Secondary parkinsonism. In: Goldensohn ES, Appel SH, ed Scientific Approaches to Clinical Neurology. Philadelphia: Lea and Febiger, 1977: 1159-89.

4 Lance JW, Adams RD. The syndrome of intention or action myoclonus as a sequel to hypoxic encephalopathy. Brain 1963; 86:111-36.

5 Crothers B, Paine RS. The Natural History of Cerebral Palsy. Cambridge: Harvard University Press, 1959: 120.

6 Paine RS. The evolution of infantile postural reflexes in the presence of chronic brain syndromes. Dev Med Child Neurol 1964; 5:345-60.

7 Marsden CD. Dystonia: The spectrum of the disease. In: Yahr M, ed The Basal Ganglia. New York: Raven Press, 1976: 351-67.

8 Lesny I. The development of athetosis. Dev Med Child Neurol 1968; 10:441-6.

9 Meyers R. Ballismus. In: Vinken PJ, Bruyn GW, eds. Handbook of Clinical Neurology. Amsterdam: North-Holland Publishing, 1968: 476-90.

10 Johnson WG, Fahn S. Treatment of hemiballism and hemichorea. Neurology (Minneap) 1977; 27: 634-6.

11 Hammond WA. A Treatise on Diseases of the Nervous System. New York: Appleton, 1871: 655-62.

12 Ringer $\mathrm{S}$. Notes of a post-mortem examination on a case of athetosis. Practitioner 1879; 23:16176.

13 Beach F. On cases of athetosis. Br Med J 1880; June 12:882-5.

14 Ferguson J. Atheto-choreic movements. N $Y$ Med J 1892; 55:657-8.

15 Alexander L. The fundamental types of histopathological changes encountered in cases of 
athetosis and paralysis agitans. Research Publications of the Association for Research in Nervous and Mental Disease 1940; 21:334-493.

16 Carpenter MB. Athetosis and the basal ganglia. Review of the literature and study of 42 cases. Arch Neurol Psychiat 1950; 63:875-901.

17 Dooling EC, Adams RD. The pathologic anatomy of posthemiplegic athetosis. Brain 1975; 98:29-48.

18 Quaglieri CE, Chun RWM, Cleland C. Movement disorders as a complication of acute hemiplegia of childhood. Am J Dis Child 1977; 131:1009-10.

19 Fahn S, Eldridge R. Definition of dystonia and classification of dystonic states. Adv Neurol 1976; 14:1-5.

20 Hanson RA, Berenberg W, Byers RK. Changing motor patterns in cerebral palsy. Dev Med Child Neurol 1970; 12:309-14.

21 Schwalbe W. Eine eigentumliche tonishe Krampfform mit hysterischen Symptomen. Inaugural Dissertation. Berlin: G. Schade.

22 Herz E. Dystonia II. Clinical classification. Arch Neurol Psychiat 1944; 51:319-55.

23 Eldridge $\mathbf{R}$. The torsion dystonias: literature review and genetic and clinical studies. Neurology (Minneap) 1970; 20:1-78.

24 Ryan DC. Dystonia musculorum deformans with report of a case in a child. Med J A ust 1950; 2: 360-2.

25 Messimy R, Diebler C, Metzger J. Dystonie de torsion du membre superieur gauche probablement a un traumatisme cranien. Rev Neurol (Paris) 1977; 133:199-206.

26 Brown-Denny D. The Basal Ganglia. London: Oxford University Press, 1962: 65.

27 Zeman W, Whitlock CC. Symptomatic dystonias. In: Vinken PJ, Bruyn GW, eds. Handbook of Clinical Neurology, Volume 6, Diseases of the Basal Ganglia. Amsterdam: North-Holland, 1968: 544-66.
28 Zeman W, Dyken P. Dystonia musculorum deformans. In: Vinken PJ, Bruyn GW, eds. Handbook of Clinical Neurology, Volume 6, Diseases of the Basal Ganglia. Amsterdam: North-Holland, 1968: 517-43.

29 Zeman W, Kaelbing R, Pasamanick B. Idiopathic dystonia musculorum deformans. II The formes frustes. Neurology (Minneap) 1960; 10: 1068-75.

30 Marsden CD, Harrison MJG. Idiopathic torsion dystonia. A review of 42 patients. Brain 1974; 97:793-810.

31 Angle CR, McIntire MS. Persistent dystonia in a brain-damaged child after ingeston of phenothiazine. J Pediatr 1968; 73:124-6.

32 Angle CR, McIntire MS, Zetterman R. CNS symptoms in childhood poisoning. Clin Toxicol 1968; 1:19-29.

33 Simpson MA. Delayed drug-induced dystonia. Letter, Br Med J 1973; 4:174.

34 Chalhub EG, DeVivo DC, Volpe JJ. Phenytoininduced dystonia and choreoathetosis in two retarded epileptic children. Neurology (Minneap) 1976; 26:494-8.

35 Crosley CJ, Swender PT. Dystonia associated with carbamazepine administration: experience in brain-damaged children. Pediatrics 1979; 63: 612-4.

36 Zeman W, Dyken P. Dystonia musculorum deformans. Clinical, genetic and pathoanatomical studies. Psychiat Neurolog Neurochirurg (Amsterdam) 1967; 70:77-121.

37 Raisman G. What hope for repair of the brain? Ann Neurol 1978; 3:101-6.

38 Bjorklund A, Stenevi U. Nerve growth factor: Stimulation of regenerative growth of central noradrenergic neurons. Science 1972; 175: 1251-3.

39 Svendgaarde N, Bjorklund A, Stenevi U. Regeneration of central cholinergic neurons in the adult rat brain. Brain Res 1976; 102:1-22. 